\title{
VOTING FOR ENVIRONMENTAL DONATIONS: EXPERIMENTAL EVIDENCE FROM MAJORCA, SPAIN
}

\author{
E. Blanco ${ }^{1}$, M.C López ${ }^{2}$, E. Coleman ${ }^{3}$ \\ DRAFT - Please do not quote without permission from the authors
}

Paper for the $13^{\text {th }}$ Biennial Conference of the International Association for the Study of the Commons (IASC), Hyderabad, India, January $10^{\text {th }}$ to $14^{\text {th }}, 2011$.

Sub-theme: Managing complex commons

\footnotetext{
${ }^{1}$ University of Innsbruck, Department of Public Finance

${ }^{2}$ Facultad de estudios ambientales y rurales, Universidad Javeriana, Colombia

${ }^{3}$ Department of Political Science, Florida State University
} 


\title{
VOTING FOR ENVIRONMENTAL DONATIONS: EXPERIMENTAL EVIDENCE FROM MAJORCA, SPAIN.
}

\begin{abstract}
We analyze group-voting on binding minimum contributions to environmental projects and assess how such institutions affect subsequent voluntary donations. Mature tourism destinations such as the island of Majorca (Spain) suffer environmental pressures caused by decades of intense tourism development, reducing the environmental quality and tourism appeal of the island. Financed from the local tax base, public administrations have developed costly projects to mitigate this degradation. Alternative fundraising policies applied in recent years include a tax to the tourism industry and more recently voluntary donations by tourists. In this paper we explore the fundraising possibilities of applying taxes and voluntary donations complementarily by using an economic field experiment with international tourists. Participants were allowed to vote to apply a minimum compulsory donation in addition to which they could make a voluntary donation. Our results show that participants only self-impose mandatory contributions when they must choose between a high or low tax, passing in some cases the high tax. In addition, we find that neither the act of voting nor the fact that a vote is actually passed changes voluntary contributions. Therefore, consistent with previous experimental literature addressing international tourists behavior, our data does not support a crowding-out of voluntary donations by the application of tourism taxes ear-marked for environmental purposes. From a policy perspective, this result supports the potential for a complementary use of taxes and voluntary donations for fundraising environmental projects in tourism destinations.
\end{abstract}

Keywords: Environmental fundraising; Economic field experiments; Taxes; Voluntary environmental donations; Tourism.

Sub-theme: Managing complex commons. 


\section{INTRODUCTION}

Researchers and policy-makers invest substantial effort to analyze the effects of indirect taxes on tourism activity (Bronham and Gangnes 1996, Jensen and Wanhill 2002, Palmer et al. 2007). Advocates of indirect taxes on tourism argue that such taxes (i) raise revenue, (ii) cover the costs of environmental public service provision, and (iii) act as a market correcting mechanism that incentivizes tourists to internalize the external costs of environmentally destructive activities (Gago et al. 2009).

In this paper we investigate, experimentally, the effects of different tax institutions in the Baleric Islands, Spain. These Islands serve almost 9 million international tourists in 2009 , which amounts to $1.25 \%$ of the tourism market worldwide, and have one of the highest tourism rates per capita in the world, with 14 tourists for every citizen. (Garín-Muñoz and Montero-Martín, 2007). Tourism Management has paid attention in the past to the specific case of the Balearic Islands tourism ecotax (Aguiló et al. 2005, Garín-Muñoz 2007, Garín Muñoz and Montero-Martín 2007, Gago et al. 2009, Palmer and Riera 2003). The ecotax was applied to overnight stays and was meant to raise money for funding environmental projects on the island. ${ }^{4}$ The rationale of the ecotax was to make international tourists contribute to the mitigation of the environmental problems derived from congestion. ${ }^{5}$ The ecotax raised almost 72 million euros in a two year implementation period (2002-2003). Despite the success in generating revenue, the tax was abolished after a new party took control of the local government. The incoming government's platform revolved around the social and political unrest derived from the ecotax. Political responses to municipal hotel room taxes have also been observed in the Dominican Republic, Puerto Rico, Mexico, and other countries (Gago et al. 2009).

Businesses are often concerned that such taxes might reduce tourist visits and thus negatively influence profits. Based on their price-elasticity estimates of tourism demand to the Spanish archipelago, Aguiló et al (2002) projected the effects of a $1 €$ tax on tourists to the Balearic Islands. Those authors estimate that such a tax results in 117,660 fewer tourists or a $1.44 \%$ decrease in the number of tourists for the year 2000. Using data from 19912003 (thus including years 2002-2003, when the ecotax was in place), GarínMuñoz (2007) estimated a negative effect of the ecotax for German tourism demand to the Balearic Islands. However, Garín-Muñoz and Montero-Martín (2007) did not find a significant effect on the number of arrivals when considering all international tourism demand for this same period. ${ }^{6}$ This latter finding is consistent with another study analyzing the impact of the $5 \%$ Hawaii

\footnotetext{
${ }^{4}$ For a more detailed description of the Balearic Islands ecotax and an economic analysis of the measure see Palmer and Riera (2003).

${ }^{5}$ Thus, as most hotel taxes, the ecotax combined the objectives of revenue collection and coverage of public services costs. Given that its purpose was not to internalize negative external costs to the environment, it cannot be considered as an environmental tax.

${ }^{6}$ The study included 14 origin countries: United Kingdom, Germany, France, Italy, Portugal, Norway, Belgium, Ireland, Netherlands, Denmark, Austria, Sweden, Switzerland and Finland.
} 
hotel room tax (which generated in $\$ 82$ million of revenue in 1990, making it the third largest source of state revenue) which did not find a statistically significant impact on visitors (Bonham and Gangnes, 1996).

Other fund-raising policies have also been explored in tourism including eliciting voluntary donations to environmental organizations from tourists. Example of such donations include direct giving to organizations addressing environmental issues in tourism destinations or volunteering while travelling (see Turner et al 2001 for an analysis of the role of UK charities in the tourism industry). After the Baleric Islands ecotax was abolished, a voluntary mechanism to receive and promote voluntary donations to environmental projects by tourists was implemented. The voluntary donations did not generate socio-political conflict as ecotax, but it did not raise comparable revenues. For example, revenues from the ecotax were about. 185,000 euros in 2007, while revenues from voluntary donations were 13,524 euros in $2008 .{ }^{7}$ The different fundraising capacity of the measures could be the result of differences in the time or environmental circumstances or because the institutional features of such arrangements have fundamentally different effects on tourism behavior. We explore in a controlled setting whether the fundraising capacity of taxes and voluntary donations by tourists significantly differ.

In this paper we explore the effect of enabling tourists to decide whether to impose or not a tax on their voluntary donations. We explore two different kinds of taxes, one low and one high. We test the effects of having a tax to check whether or not this tax will crowd-out voluntary donations. Further, we include two treatments where participants have the possibility to vote. In the first one by majority rule the participants decided whether they wanted the group to have a compulsory high donation or a low one; and in the second one again by majority rule the participants have the option to vote for a high donation or for not having a tax all. We address whether the fundraising capacity of taxes varies when groups of tourists are offered the possibility to vote to impose such obligatory burden to the group. In particular we want to address the question of how endogenous choice of rules (by voting) affects the level of contribution in a donation setting.

In doing so, we diverge from previous analysis of the economic impact of the Balearic Islands ecotax, which was based on analyses of tourism demand. Instead we make use of a very different methodology by using economic experiments. Economic experiments ${ }^{8}$ are controlled games used to study economic questions (Friedman and Sunder, 1994). In this setting, an experimenter creates an environment where a number of participants make decisions in a controlled setting. The incentives of behavior introduced by monetary payments or other important rewards. Experiments are used

\footnotetext{
${ }^{7} 2007$ is the only year for which the FSB (the Foundation for a Sustainable Development of the Balearics Islands) has presented their accounting balance, and therefore the only official accounting information availableat the moment where this paper was finished. Receipts for 2008 correspond to data published in regional newspapers regarding an investigation to the FSB's accounting system (http://www.diariodemallorca.es/mallorca/2010/07/05/auditoriadesvela-descontrol-venta-tarjeta-verde-hoteles/584239.html), 5 July 2010.

${ }^{8}$ These experiments are also conducted in psychology and political science.
} 
according to Smith (1994) to: a) to test a theory or to discriminate between theories; b) to explore the causes of a theory failure; c) to establish empirical regularities as a basis for new theory; d) to compare environments; e) to compare institutions; f) to evaluate policy proposals; and g) to test ground for institutional design. Experiments related to environmental and resources economics are quite diverse and range from ways to improve cost benefit analysis to resource use and regulations (List 2006). However the use of experiments in tourism economics have been very limited.

The use of this methodology in tourism studies is very recent. To the best of our understanding, only two papers have used this methodology for studying issues related with tourism. Alpízar et al (2008a) and Alípzar et al (2008a) conduct natural experiments with international visitors to a Costa Rican National Park. In a natural experiment ${ }^{9}$ individuals are not aware of their participation in an experiment, since the experimenter modifies a decision-making context which individuals are facing in real life. Alpízar et al (2008b) test for the effect of anonymity, reciprocity and reference contributions on donations to the park. In this same setting, Alípzar et al (2008b) analyze whether respondent donations to the national park are more sensitive to anonymity and reference contributions when making a hypothetical choice compared to a choice that involves an actual payment to the park. They found evidence of a large hypothetical bias, thus stressing the relevance of using actual payments in research with tourists as subject pools than eliciting state preferences willingness to pay. Therefore, we use a framed field experiment ${ }^{10}$ methodology instead of stated preferences to improve the reliability of our findings. López et al. (forthcoming) also make use of a framed field experiment in a tourist setting. They explore different fundraising mechanisms for environmental projects (including voluntary donations, taxes- as we do-, and matching instruments) but do not consider the effect of allowing subjects to vote on the imposition of taxes. Our paper contributes to this literature by comparing voluntary donations to environmental projects in contexts where taxes are self-imposed by participants.

In the economic literature the effects of voting has been explored in different settings. Knox and Meinzen-Dick (1999) claim that voting is a way to communicate and to generate commitment among voters. This hypothesis has been tested with economic experiments by different authors. Tyran and Feld's (2006) reported that contribution to a group account, in a public good experiment ${ }^{11}$ increases when the group votes for a specific law compared to the contributions to the group when face the tax exogenously. In that sense when voting participants are giving support to something they think may be useful,

\footnotetext{
${ }^{9} \mathrm{~A}$ natural field experiment is one where "where the environment is one where the subjects naturally undertake these tasks and where the subjects do not know that they are in an experiment" (page 1014, Harrison and List 2004)

${ }^{10}$ According to the taxonomy of Harrison and List (2004), our experiment is a framed field experiment. Our subject pool was drawn from tourists while vacationing in the Island of Majorca. ${ }_{11}$ In a public good experiment a group of participants have a limited endowment which they can keep for themselves or they can contribute to a group account. Each unit contributed to the group account has a lower individual value, and a higher social value, than a unit kept for oneself. The best strategy for the group is to contribute all endowments, but since there are individual incentives to free-ride, the economic prediction is that no one will contribute to the group account.
} 
therefore this is interpreted as a signal of cooperation. Sutter, Haigner and Kocher (2010) explore in a public good game the effect of voting for the possibility of rewarding or punishing other group members. Their results support that when the group has the possibility to vote, there is a positive effect on cooperation levels compared to a setting in which the same institutions have been determined exogenously (by the experimenter). This suggests that participation rights enhance cooperation Rauchdobler et al. (2009) create an experiment to test the effect of a public good threshold approved in a referendum compared to one imposed exogenous. They found that voting has signaling and commitment effects but they are not strong enough to significantly improve the efficiency compared to external thresholds.

\section{EXPERIMENTAL RESEARCH}

The research presented in this paper is based in a modified dictator game $^{12}$. In this game a player (donor) is endowed with money and her task is to choose the amount to share with another subject (recipient). The payoffmaximizing behavior is for donors to keep all endowment for themselves and donate nothing to recipients. However, the behavior of subjects in this game is well documented to deviate from the expected take-all behavior (e.g. Cherry et al 2002). In a dictator game there is no interaction between participants (donor and recipient are anonymous in the sense that neither knows the identity of the other) and is normally a one-shot choice, so there are no confounding issues arising from strategic behavior, reputation building, cooperation, etc. (Munro and Valente, 2010).

In our case, tourists participating in the experiment are the donors and the recipient is an environmental foundation ${ }^{13}$,the Foundation for a Sustainable Development of the Balearics Islands ${ }^{14}$ (FSB for short). Therefore, each participant was asked to allocate the endowment they received when starting the experiment between herself and a public good cause, i.e. environmental preservation.

A closely related paper to our study is Ekel and Grossman (1996). This paper makes use of a double-anonymous dictator game to explore charity donations by replacing the recipient by an established charitable organization (the American Red Cross). Findings in Ekel and Grossman (1996, p.188) support that "altruistic behavior increases in dictator games when the recipient is a legitimate charity as opposed to an anonymous person who the subjects can infer is drawn from the same population as themselves". This could possibly be an explanation of the high donation levels of subjects in the baseline treatment of our experiments presented in section 4. In a similar paper Munro and Valente (2008) substitute the recipient either by a pure or impure public

\footnotetext{
${ }^{12}$ This game was first used to test whether people was self interested as traditional economic theory predicts (Forsythe et al, 1994; Hoffman et al, 1996).

${ }^{13}$ In our case, the donors knew from the beginning that the recipient of the money was going to be the FSB, in that sense the experiment is not a pure Dictator Game.

${ }^{14}$ A public-private non-profit organization on charge of collecting the voluntary donations (Green Card) that tourists and residents can buy in different places around the Island (hotels, tourism information points, car rentals, natural protected areas, etc.) to fund environmental projects.
} 
good. These authors refer to the latter as private goods bundled with a type of environmental offset or contribution to reduce environmental externalities. Their results show that participants' decisions change significantly when offered impure public goods as opposed to pure public goods, and this finding may support the desire of participants to "get away" from a decision task not to be altruistic.

\section{EXPERIMENTAL DESIGN}

We conducted a series of field experiments at the end of the summer of 2009 (end of the high tourism season) in the Island of Majorca. The experiments were conducted by three researchers fluent in English ${ }^{15}$ (two of them co-authors of this paper). We used two different recruitment processes. First, we recruited participants at the departure gates of Palma de Majorca Airport, which is the common practice when doing economic analyses of tourism demand. Second, we recruited tourists through the University of the Balearic Islands. These participants were tourists in Majorca taking some academic courses during their stay in the island. In total 174 tourists $^{16}$ participated in our experiments.

The recruitment process differs according to the location where the experiment was conducted. At the airport each tourist, after being seated in his departure gate, was approached by one of the members of the research team and asked to participate in a research project about environmental policy ${ }^{17}$. In the University recruitment, the participants were assisting to an activity organized for international visitors, when they were invited to participate. The same procedures regarding the experiment were followed both at the airport and at the University, thus the research project was described as a single decision-making task to last no more than 10 minutes, and where the participant could have the opportunity to earn some money. We explicitly mentioned that their contact information was not requested in the study, as this appeared to be a major concern before agreeing to participate. ${ }^{18}$

After agreeing to participate, each subject was handed a folder with three pieces of paper. The first sheet of paper explained that the research was a joint effort of researchers from the University of the Balearic Islands (Spain), Florida State University (US), and Pontificia Universidad Javeriana (Colombia), that participation was voluntary, and that all information was to be treated confidentially. Additionally, a description of the mission and main objectives of the FSB was provided. Then, an explanation of the decision task, followed by

15 All the experiments were conducted in English for three reasons: British tourists are the second major market for Majorca tourism attractions, classes for the international students going for an exchange short period to the University of the Balearic Islands are taught in English and finally the budget of the project did not allow us for translation to other languages.

${ }_{16} 118$ of these tourists participated in the experiment at the airport; the remaining 56 participated through the University in their first week in the island.

${ }^{17}$ Each one of the researchers was wearing a t-shirt from the University of the Balearics Islands and had a formal identification with a picture provided and signed by the airport authorities.

18 The design of the experiment and the survey were carefully constructed in such a way that we did not ask for any information that will give us the possibility to have future contact with the participants. This was done to ensure the transparency of the purpose of the research. 
an example was given. In the second piece of paper, participants were asked to privately make their decision. The third sheet presented a questionnaire with socio-economic information and information regarding their experience as a tourist on the island. We answered any questions they had about how to fill the questionnaires when required. Since participation was absolutely voluntary, subjects were free to decline participation at any point.

The experimental design includes six different treatments, all based in a modified dictator game. In the first treatment, the baseline treatment, the participant was endowed with 15 euros $^{19}$ and was asked to choose the amount of money he/she wanted to give to the Foundation for a Sustainable Development of the Balearics Islands. We explained his/her earnings would consist of the money he/she decided to keep, the portion of the 15 euros he/she was not giving to the FSB.

The second treatment is the low tax treatment. As in the baseline treatment, each participant started with 15 euros, but in this case he/she was told that 5 euros of this 15 euros were given compulsory the FSB. Then, his/her task was to decide what to do with the remaining 10 euros. The third treatment, the high tax, was similar to the previous one, but in this case 10 euros out the initial 15 euros were compulsory given to the FSB. His/her decision was to decide whether and how much to give from the reaming 5 euros.

The fourth treatment was the vote low tax treatment. Participants were assigned to a group of five people ${ }^{20}$.Each participant in the group started with 15 euros and was asked to make two decisions tasks. The first decision was to anonymously vote on whether to have a compulsory allocation of 5 euros from every member of the group to give to the FSB. If at least 3 members of the group voted yes then it became compulsory that each group member had to give 5 euros from their 15 euros to the FSB. Depending on voting results, participants for the second decision ended up playing either the baseline treatment (if less than three votes were yes) or the low tax treatment (if more than three votes were yes).

In the fifth and last treatment, the vote low/high tax treatment participants were also assigned to play in a group of five. Each participant was endowed 15 euros. Like in the previous treatment each individual was asked to make two decisions tasks. First, to vote on whether to have a compulsory allocation of 5 euros or one of 10 euros from every member of the group to give to the FSB. The allocation with at least three votes was then selected for the second task of the treatment. If at least 3 members of the group voted for low, then it became compulsory that each group member had to give 5 euros from their 15 euros to the FSB (playing the low treatment), but if at least 3 members of the group voted for high, then it became compulsory that each group member had to give 10 euros from their 15 euros to the FSB (playing the high treatment). A summary of the participants and groups in each treatment is provided in table 1:

\footnotetext{
${ }^{19}$ At the time of the experiment 1 euro was equivalent to US\$1.47.

${ }^{20}$ Participants never knew the identity of the other members of their group.
} 
Table 1: Summary of participants in the different treatments.

\begin{tabular}{|l|l|l|}
\hline & Participants & Groups \\
\hline Baseline & $\begin{array}{l}16 \text { students } \\
30 \text { airport }\end{array}$ & \\
\hline Low tax & 30 & 6 \\
\hline High tax & {$[\mathrm{EB} 128$} & 6 \\
\hline Vote low tax & 20 & 4 \\
\hline Vote high/low tax & 20 & 4 \\
\hline
\end{tabular}

For all treatments, the money donated to the FSB was placed in a sealed envelope with the participant number in front of each participant and handled at the end of all sections to the FSB. At the end of the experiment, we told each participant that they could contact the FSB to check that their donation was received. ${ }^{21}$ To facilitate them this process, we gave each participant the first sheet of paper containing the information about the FSB, their e-mail and telephones. Additionally, we wrote their participant number as a mean to track their donation.

Each of the participant's potential earnings varied depending on the treatment of participation: from a maximum of 15 euros in the baseline, and vote low treatments; with 10 euros in the low tax, vote low and low/high tax vote treatments; and a minimum of 5 euros in the high tax and/high tax vote treatments. Average earnings across treatments 5.51 euros, with maximum earnings of 15 euros (implying no contributions to the FSB in the baseline, and vote low treatments) and a minimum of 0 euros (implying full contributions to the FSB).

\section{RESULTS}

Table 2 shows the summary statistics by treatment both for total contributions and for voluntary contribution. Total contribution to the FSB consists of the sum of the tax and voluntary contributions in the tax treatments. The voluntary contribution is the amount that is voluntarily given to the FSB in the different treatments. In the high tax treatment, for example, the maximum voluntary contribution is 5 euros, in the low tax treatment the maximum is 10 euros, and in the baseline treatment the maximum voluntary contribution is 15 euros.

Among the non-voting treatments, the baseline treatment is the one with the lowest contribution levels. This is the case despite the fact that participants were contributing more than half of their endowment ( 7.78 euros out of 15 euros initially endowed). The comparison of the voting treatments with respect to the

\footnotetext{
${ }^{21}$ According to the FSB, no participant contacted them to verify that a donation was made under their participant number.
} 
tax treatments with no voting shows that total contributions in the voting treatments are substantially smaller than when no voting is permitted (about 14 euros in the high tax vs. slightly more than 9 euros in the vote high/low tax treatment, and 12.5 euros in the low tax treatment vs. 3 euros in the low tax treatment with voting). However, when voluntary donations are taken as the relevant variable, differences between the high tax and the vote high/low tax disappear ( $p$-value $=0.87$ ) and only persists the difference between the low tax vs. low tax treatments $(p-v a l u e=0.00)$.

Table 2. Summary Statistics by Treatment Condition*

\begin{tabular}{|c|c|c|c|c|c|}
\hline & Baseline & $\begin{array}{l}\text { High } \\
\text { Tax }\end{array}$ & $\begin{array}{l}\text { Low } \\
\text { Tax }\end{array}$ & $\begin{array}{c}\text { High/Low } \\
\text { Tax Vote }\end{array}$ & $\begin{array}{c}\text { Low } \\
\text { Tax } \\
\text { Vote }\end{array}$ \\
\hline Total & 7.78 & 14.036 & 12.500 & 9.150 & 3.000 \\
\hline Contribution & (5.87) & (1.89) & $(2.87)$ & (3.05) & (2.88) \\
\hline Voluntary & 7.78 & 4.036 & 7.500 & 4.15 & 3.000 \\
\hline Contribution & (5.87) & (1.89) & (2.87) & (3.23) & $(2.88)$ \\
\hline Number of & 6.36 & 8.964 & 10.667 & 2.125 & 3.538 \\
\hline Visits & $(10.49)$ & $(11.74)$ & $(22.30)$ & (2.31) & (8.03) \\
\hline \multirow[t]{2}{*}{ Age } & 2.088 & 2.143 & 2.767 & 1.000 & 1.067 \\
\hline & (1.10) & $(1.1)$ & (1.19) & $(0.00)$ & $(0.26)$ \\
\hline \multirow[t]{2}{*}{ Education } & 4.66 & 4.464 & 4.333 & 4.706 & 4.867 \\
\hline & (0.67) & (0.92) & (0.92) & $(0.77)$ & $(0.83)$ \\
\hline Observations & 46 & 28 & 30 & 20 & 20 \\
\hline
\end{tabular}

In[m2] the high/low tax vote treatment, $75 \%$ of the participants vote for low tax and $25 \%$ vote for high tax. Then only one group play with high tax and the other four with low tax. On the other hand for the low vote tax, $75 \%$ of the participants vote for no tax (i.e baseline) and $25 \%$ vote for low. With this treatment any of the groups reached the majority rule, there for all the groups play with baseline. This result explains what we described before, the contributions with these two treatments were as low because when voting participants were signaling the fact that they did not want to contribute to the FSB. Several may explain the lower voluntary contributions in the low tax treatment. Although both set of experiments were conducted with tourists, there are some differences between these two experimental settings. The first experiments were conducted in the airport and the second ones at the University. We are aware that tourists in Majorca are afraid of swindlers and it may be possible that at the airport they were more cautious about the money than those who were recruited with support from the University. A second reason to explain the differences in behavior may come from the fact that despite both groups had stayed in Majorca for a similar time period, one was about to leave the island while the other group was just at the beginning of their trips, therefore the need for this extra cash could be totally different in both samples. Finally as observed in table 1, the groups have some differences in terms of age and in terms of number of visits to Majorca. In another paper Lopez et al. (forthcoming) explore if these variables explain the contributions under low, high, baseline and matching treatments not finding any significant influence on behavior in any treatment. 
To analyze our data more rigorously we create two models presented in table 3. The dependent variable of both models is voluntary contributions to the FSB. Table 3 shows how both voting treatments have a negative influence on voluntary donations with respect to the baseline treatment, but only the high/low vote it is statistically significant at the $1 \%$ in both models. Further, the data reveals that voluntary contributions of the high tax treatment are significant lower than the voluntary contribution of the baseline treatment in the first treatment and the low tax treatment has a significantly negative influence on voluntary donations. Lastly, only age seem to have a positive relation with the amount of money contributed to the FSB.

Table 3: Voluntary Contrubutions

\begin{tabular}{|c|c|c|}
\hline & $\begin{array}{l}\text { OLS } \\
\mathrm{b} / \mathrm{se}\end{array}$ & $\begin{array}{l}\text { OLS } \\
\mathrm{b} / \mathrm{se}\end{array}$ \\
\hline Vote High/Low Tax & $-3.74^{\star \star \star}(0.96)$ & $-3.77^{\star \star \star}(0.88)$ \\
\hline Vote Low Tax & $-0.28(0.93)$ & $-1.48(0.89)$ \\
\hline Hightax & $-3.63^{* *}(1.07)$ & $-1.53(0.96)$ \\
\hline Low Tax & $-4.78^{\star \star \star}(1.07)$ & $-2.23^{*}(1.2)$ \\
\hline Times Visit & & $-0.02(0.027)$ \\
\hline Age & & $1.95^{\star \star \star}(0.36)$ \\
\hline Education & & $0.56(0.42)$ \\
\hline \multirow[t]{2}{*}{ Constant } & $7.78^{* * *}$ & 3.21 \\
\hline & $(0.59)$ & (2.31) \\
\hline R-Squared & 0.20 & 0.34 \\
\hline Adj. R-Squared & 0.18 & 0.30 \\
\hline $\mathrm{F}$ & $8.83^{* * *}$ & $9.19^{\star * \star}$ \\
\hline $\mathrm{N}$ & 144 & 131 \\
\hline
\end{tabular}

\section{CONCLUSION}

This paper addresses the voluntary donations to environmental projects by tourists and how these donations are influenced by the capacity of tourists to decide whether to self-impose a tax to force contributions or not.

This first exploration of results shows that it is very seldom that tourists vote to establish a tax with majority rule or the higher of two tax options. Most groups fail to reach enough members supporting the tax. Only in one of the high/low tax vote groups the high tax was established, imposing a 10 euros compulsory contribution to all participants in the group. It can generally be said thus that the voting treatments fail to impose taxes or higher taxes on group members. Maybe this result is due to the fact that tourists do not feel they may have to pay for environmental services provided by the destinations.

Further, we explore voluntary donations in voting treatments as compared with non-voting treatments and we see that the failure to impose the low tax seems to send a signal to participants to reduce voluntary contributions. 
Since the group cannot achieve a majority supporting a 5 euros tax compulsory to all members, each participant may think that others will contribute low voluntary amounts and contribute themselves in low amounts. This result differs from previous results in public goods literature insofar the public good to which participants contribute is the good environmental quality in Majorca, which has million of users, and is not restricted to the users participating in their group in the experiment. 


\section{References}

Aguiló, E., Riera, A., and Rosselló, J. (2005) The short-term price effect of a tourist tax through a dynamic demand model: The case of the Balearic Islands. Tourism Management, Vol. 26, pp. 359-365.

Alpizar, F, Carlsson F., and Johansson-Stenma, O. (2008a) Does context matter more for hypothetical than actual contributions? Evidence from a natural field experiment. Experimental Economics, Vol. 11, pp. 299-314.

Alpizar, F., Carlsson F., and Johansson-Stenman, O. (2008b) Anonymity, reciprocity, and conformity: Evidence from voluntary contributions to a national park in Costa Rica. Journal of Public Economics, Vol. 92, pp. 1047-1060.

Baker, R., Walker, J., and Williams, A. (2009) Matching contributions and the voluntary provision of a pure public good: Experimental evidence. Journal of Economic Behavior and Organization, Vol. 70, pp. 122-134.

Bonham, C.S., and Gangnes, B. (1996) Intervention analysis with cointegrated time series: The case of the Hawaii hotel room tax. Applied Economics, Vol. 28, pp. 1281-1293.

Cherry, T.L., Frykblom, P., and Shogren, J.F. (2002) Hardnose the dictator. American Economic Review, Vol. 92, pp. 1218-1221.

Eckel, C.C. and Grossman, P.J. (1996) Altruism in anonymous dictator games. Games and Economic Behavior, Vol. 16 No 2., pp. 181-191.

Forsythe, Robert; Horowitz, Joel; Savin, N. E. and Sefton, Martin. 1994. "Replicability, Fairness and Pay in Experiments with Simple Bargaining Games." Games and Economic Behavior.6, 347-69.

Friedman Daniel and Shyam Sunder. 1994. Experimental Methods: A Primer for Economists, Cambridge University Press

Harrison, G.W. and List, J. (2004), "Field experiments", Journal of Economic Literature, Vol. 42 No. 4, pp. 1009-1055.

Gago, A., Labandeira, X., Picos, F., and Rodríguez, M. (2009) Specific and general taxation of tourism activities. Evidence from Spain. Tourism Management, Vol. 30, pp. 381-392.

Garín-Muñoz, T. (2007) German demand for tourism in Spain. Tourism Management, Vol. 28, pp. 12-22.

Garín-Muñoz, T. and Montero-Martín, L.F. (2007) Tourism in the Balearic Islands: A dynamic model for international demand using panel data. Tourism Management, Vol. 28, pp. 1224-1235.

Hoffman, Elizabeth, Kevin McCabe, and Vernon L. Smith. 1996. "Social Distance and Other- Regarding Behavior in Dictator Games." American Economic Review. 86.3: 653-660.

Jensen, T.C. and Wanhill, S. (2002) Tourism's taxing times: value added tax in Europe and Denmark. Tourism Management, Vol. 23, pp. 67-79.

Knox, A., and R. Meinzen-Dick. 1999. "Collective Action, Property Rights, and Devolution of Natural Resource Management: Exchange of Knowledge and Implications for Policy."CAPRi Working Paper 11, Washington: International Food Policy Research Institute.

List, John. 2006 Using Experimental Methods in Environmental and Resource Economics. Edward Elgar Publishers. Edited.

López, M.C.; Blanco, E.; and Coleman, E. (forthcoming) An experimental study for environmental fundraising in Majorca, Spain. In R.M. Isaac and D. A. 
Norton, eds., Research in Experimental Economics Volume 14, Bingley, U.K.: Emerald, 2011. (Peer Reviewed Chapter)

Munro, A. and Valente, M. (2008) Green goods: are they good or bad news for the environment? Evidence from a laboratory experiment on impure public goods. MPRA Paper No. 13024. Online at http://mpra.ub.unimuenchen.de/13024/

Palmer, T. and Riera, A. (2003) Tourism and environmental taxes. With special reference to the "Balearic ecotax". Tourism Management, Vol. 24, pp. 665-674.

Palmer, T., Riera, A., and Rosselló, J. (2007) Tourism's taxing times: value added tax in Europe and Denmark. Tourism Management, Vol. 28, pp. 271-279.

Rauchdobler, Julian., Sausgruber, Rupert., and Tyran, Jean-Robert. (2009). Voting on thresholds for public goods: experimental evidence. Discussion papers, department of Economics, University of Copenhagen. http://ssrn.com/abstract $=1529270$

Smith, V., 1994. Economics in the Laboratory. Journal of Economic Perspectives, 8(Winter), 113-131

Sutter, M., Haigner, S., and Kocher, M. G. (2010). Choosing the stick or the carrot? endogenous institutional choice in social dilemma situations. The Review of Economic Studies. Volume 77, (4), 1540- 1566

Turner, R., Miller, G., and Gilbert, D. (2001) The role of UK charities and the tourism industry. Tourism Management, Vol. 22, pp. 463-472.

Tyran, J-R, and L. P. Feld. 2006. "Achieving compliance when legal sanctions are non-deterrent." Scandinavian Journal of Economics 108(1), 135-156. 
